ORIGINAL

\title{
Uso de una conantokina y anticuerpos policlonales para identificar la subunidad NR2B del receptor n-metil-d-aspartato
}

\section{The use of conantokin and polyclonal antibodies to identify the NR2B subunit of the n-methyl-d-aspartate receptor}

\author{
Edwin Reyes $\mathrm{G},{ }^{1}$ Lic. Química, Edgar Reyes $\mathrm{M},{ }^{1 *} \mathrm{Ph} . \mathrm{D}$, Leonardo Lareo, ${ }^{2} \mathrm{Ph} . \mathrm{D}$
}

\begin{abstract}
${ }^{1}$ Universidad Nacional de Colombia. Departamento de Química. Grupo de Investigación en Proteínas (GRIP). Cra 30 calle 45. Edificio 451. Laboratorio 201-1 Bogotá, D.C., Colombia. ${ }^{2}$ Pontificia Universidad Javeriana, Departamento de Nutrición y Bioquímica, Bogotá, D.C., Colombia. †In Memoriam. *Correspondencia: eareyesm@unal.edu.co
\end{abstract}

Recibido: Marzo 23 de 2010; Aceptado: Agosto 25 de 2010

\section{RESUMEN}

Objetivo. Proponer una metodología de identificación de la subunidad NR2B, mediante el uso de conantokina G, así como una adecuada extracción de la subunidad NR2B. Materiales y métodos. Se ensayaron dos metodologías para la extracción de la subunidad NR2B de cerebro de rata adulta, la primera buscó la extracción de la subunidad a partir de la membrana mediante la utilización del detergente deoxicolato de sodio y la segunda, garantizó primero la solubilización y eliminación de proteínas citoplasmáticas para luego realizar la extracción de la subunidad mediante el uso del mismo detergente, a partir del pellet generado en la centrifugación del extracto obtenido. Adicionalmente se biotiniló la conantokina G para evaluar su eficiencia en la identificación de la subunidad y comparar los resultados con los obtenidos por metodologías tradicionales como DOT-BLOT, WESTERN-BLOT, ELISA e Inmunohistoquímica. Resultados. La segunda metodología mostró mayor extracción de NR2B por lo que se seleccionó para la realización de los extractos posteriores. Los ensayos de identificación con la conantokina biotinilada evidenciaron interferencia en el reconocimiento, haciéndose necesaria la identificación de la presencia de la subunidad NR2B mediante el uso de anticuerpos policlonales en los ensayos mencionados. Conclusiones. Se propone que hay un impedimento de tipo estérico en el marcaje de la conantokina con la biotina lo que no favorece la interacción de este péptido con la subunidad.

Palabras clave: Receptor, N-metilaspartato, conantokina-G, cerebro, biotina. 


\section{ABSTRACT}

Objective. To propose a methodology that identifies the NR2B subunit through the use of conantokin G, as well as an adequate extraction of the NR2B subunit. Materials and methods. Two methodologies were tested for the extraction of the NR2B subunit of the adult rat, the first one sought the extraction of the subunit through a membrane by using sodium deoxicolate; and the second, guaranteed the solubilization and elimination of cytoplasmic proteins, in order to later extract the subunit through the use of the same detergent from the pellet resulting from the centrifugation of the obtained extract. Additionally, the conantokin $\mathrm{G}$ was biotynilated in order to evaluate its efficiency to identify the subunit and to compare the results obtained from traditional methodologies such as DOT-BLOT, WESTERN-BLOT, ELISA and Immunohistochemical. Results. The second methodology showed a greater extraction of NR2B, thus it was chosen for the subsequent extracts. The identification tests with biotynilated conantokin showed interference in recognition, thus, it was necessary identify the subunit NR2B through the use of the polyclonal antibodies mentioned in the tests. Conclusions. An impediment of esteric character is proposed in marking the conantokin with the biotin, which does not favor the interaction of this peptide with the subunit.

Key words. Receptor, N-methyl aspartate, conantokin G, brain, biotin.

\section{INTRODUCCIÓN}

El receptor de glutamato tipo NMDA es un canal iónico heteromérico dependiente de ligando, que interactúa con múltiples proteínas intracelulares por medio de sus diferentes subunidades (1). Se encuentra concentrado en regiones postsinápticas y en menor proporción en sitios presinápticos (2), involucra una variedad de procesos de plasticidad neuronal como aprendizaje y memoria. Su sobreestimulación produce enfermedades neurodegenerativas, las cuales se relacionan con el flujo excesivo de calcio. A nivel neuronal se distinguen funciones como: activación del receptor tipo NMDA asociada con la larga duración de cambios en energía sináptica (3), organización de fibras aferentes con respecto a la duración del desarrollo neuronal (4) y participación en la neurotoxicidad del glutamato.

Este receptor se divide en siete genes que codifican cada una de sus subunidades. El gen GRIN1 codifica la subunidad NR1, que es un componente principal para la funcionalidad del receptor. Existe cierta heterogeneidad de la subunidad NR2 ya que presenta cuatro subtipos NR2A-NR2D, que poseen perfiles de expresión específicos dentro del cerebro $(5,6)$; la subunidad NR3 presenta dos subtipos NR3A y $\operatorname{NR3B}(7,8)$.
La subunidad NR2B del receptor NMDA presenta cuatro dominios transmembranales putativos, M1-M4 (9), donde el M2 forma un loop reentrante similar a la subunidad NR1 (10). Es abundante en hipocampo y corteza cerebral (5), adicionalmente, se ha caracterizado en zonas sensoriales, motoras y en estructuras asociadas con el sistema límbico. Al utilizar antagonistas selectivos para NR1/NR2B, se confirmó su presencia en cuerpos celulares de neuronas corticales maduras y alta expresión de la subunidad durante la maduración de neuronas dentro de membranas plasmáticas y neuronas de hipocampo (11). La subunidad NR2B no se encuentra expresada significativamente en hipotálamo y en tálamo, aún así es responsable de muchas funciones regulatorias dentro de estas dos regiones del sistema nervioso central $(6,12)$.

La conantokina $G$, una conotoxina aislada del veneno de Conus geographus, es un péptido marino de 17 aminoácidos que se caracteriza por la presencia de cinco residuos de ácido $\gamma$-carboxiglutámico (G-E$\gamma-\gamma-\mathrm{L}-\mathrm{Q}-\gamma-\mathrm{N}-\mathrm{Q}-\gamma-\mathrm{L}-\mathrm{I}-\mathrm{R}-\gamma-\mathrm{K}-\mathrm{S}-\mathrm{N}-\mathrm{NH}_{2}$ ) (13). Muestra alta selectividad y antagonismo para la subunidad NR2B del receptor NMDA. Esta toxina produce hiperactividad, 
y demuestra ser un potente bloqueador competitivo de las actividades del receptor NMDA, también se ha demostrado que es neuroprotectora en el modelo de isquemia cerebral transitoria en ratas (14) y ha sido activa en el modelo de enfermedad de Parkinson (15). A este grupo también pertenecen las conantokinas $R, L$ y $T$ que, de la misma manera, han demostrado su potencial como anticonvulsionantes (16).

El objetivo de este estudio fue proponer una metodología de identificación de la subunidad NR2B, mediante la utilización de conantokina G.

\section{MATERIALES Y MÉTODOS}

Métodos de extracción. Se usaron dos métodos para la extracción del receptor tipo NMDA como complejo.

Metodología 1. Se homogenizaron 5 cerebros de rata adulta wistar con buffer de extracción (Tris- $\mathrm{HCl} 50 \mathrm{mM} \mathrm{pH} 9.0$ e inhibidores de proteasas PMSF 10 mM, EDTA $100 \mathrm{mM}$, leupeptina $1 \mu \mathrm{g} / \mathrm{mL}$, pepstatina 1 $\mu \mathrm{g} / \mathrm{mL}$ y deoxicolato de sodio al $1 \%(\mathrm{p} / \mathrm{v})$ ) y se incubaron a $37^{\circ} \mathrm{C}$ durante 1 hora (17). Posteriormente el extracto se centrifugó a $18000 \mathrm{rpm}$ por 1 hora a $4^{\circ} \mathrm{C}$ en centrifuga Sorvall RC5C. El pellet se conservó a $-30^{\circ} \mathrm{C}$ y el sobrenadante se dializó contra 10 volúmenes de Tris- $\mathrm{HCl} 50 \mathrm{mM} \mathrm{pH} \mathrm{7.5;}$ Tritón X-100 0.1\% en agitación constante, realizando tres cambios de buffer de diálisis.

Metodología 2. Se trataron 5 cerebros de rata adulta wistar con buffer HEPES 10 $\mathrm{mM} \mathrm{pH} 7.4(\mathrm{NaCl} 137 \mathrm{mM} ; \mathrm{KCl} 4.6 \mathrm{mM}$; $\mathrm{KH}_{2} \mathrm{PO}_{4} 1.1 \mathrm{mM}$; $\mathrm{MgSO}_{4} 0.6 \mathrm{mM}$; EDTA $1.1 \mathrm{mM}$ ) e inhibidores de proteasas (PMSF $0.5 \mathrm{mM}$, EDTA $2.5 \mathrm{mM}$, leupeptina $1 \mu \mathrm{g} /$ $\mathrm{mL}$, pepstatina $1 \mu \mathrm{g} / \mathrm{mL}$ ). Con el extracto obtenido se realizaron centrifugaciones a $18000 \mathrm{rpm}$ durante 1 hora a $4^{\circ} \mathrm{C}$ en centrifuga Sorvall RC5C. El pellet obtenido se resuspendió en buffer de extracción descrito en la metodología 1 , continuando con su tratamiento de acuerdo con lo descrito en esa metodología.
Purificación preliminar por cromatografia de exclusión molecular. Los extractos obtenidos de ambas metodologías se purificaron preliminarmente con una columna de exclusión molecular Sephacryl S-200 (volumen de soporte $226 \mathrm{~mL}$ ) realizando siembras de $5 \mathrm{~mL}(4 \mathrm{mg} / \mathrm{mL})$ y eluyendo con buffer Tris- $\mathrm{HCl} 50 \mathrm{mM} \mathrm{pH}$ 7.5; Tritón $\mathrm{X}-1000.1 \%$, con un volumen muerto aproximado de $70 \mathrm{~mL}$. Se colectaron volúmenes de $1 \mathrm{~mL}$ realizando seguimiento de proteína mediante absorbancia a 280 $\mathrm{nm}$. Los tubos que presentaron mayor absorbancia se reunieron para formar las fracciones I y II de acuerdo con el perfil cromatográfico I. La fracción I corresponde al volumen muerto de la columna.

Concentración. Las fracciones I y II (FI y FII) obtenidas a partir de la cromatografía de exclusión molecular se concentraron, mediante ultrafiltración con membrana AMICON YM100. El volumen de extracto concentrado obtenido fue diez veces menor que el volumen de las fracciones iniciales.

\section{Cromatografia de afinidad unando} sepharosa 4B-NHS-Glu. Se utilizaron 2 $\mathrm{mL}$ de Sepharosa 4B-NHS (Pharmacia $($ ) ) a la cual se le acopló glutamato (Glu 2.0 M), de acuerdo con las siguientes condiciones (18): se tomaron $2 \mathrm{~mL}$ de sepharosa 4B y se lavaron con $2 \mathrm{~mL}$ de agua, seguido de dos lavados con $2 \mathrm{~mL}$ de $\mathrm{NaOH} 1 \mathrm{M}$. Posteriormente se suspendió en igual volumen de soporte una solución $1 \mathrm{M}$ de $\mathrm{NaOH}$ más $200 \mu \mathrm{L}$ de butanediolglicileter y $2 \mathrm{mg}$ de $\mathrm{NaBH}_{4}$. Se mantuvo en agitación toda la noche a temperatura ambiente y se lavó el gel varias veces con agua, solución $\mathrm{NaCl} 1 \mathrm{M}$ y de nuevo con agua. El glicidol modificado obtenido fue oxidado con periodato. Para esto, se lavó la sepharosaepoxi activada con una solución de $\mathrm{NH}_{4} \mathrm{OH}$ $1 \mathrm{M}$ y luego se suspendió en esta misma solución. Se mantuvo a $40^{\circ} \mathrm{C}$ en agitación por 3 horas. Posteriormente, se enfrió la mezcla de reacción y se lavó con agua, solución de $\mathrm{NaCl} 1 \mathrm{M}$ y de nuevo con agua. Se adicionó metperiodato de sodio $\left(\mathrm{NaIO}_{4}\right.$ $0.2 \mathrm{M}$ ) al gel, agitando y manteniendo a temperatura ambiente por $90 \mathrm{~min}$. Se lavó 5 veces con agua. Seguidamente, se lavó con 10 volúmenes del buffer de 
acople (buffer fosfato $0.1 \mathrm{M}, \mathrm{pH}$ 7.0). Se adicionaron al soporte, $2 \mathrm{~mL}$ de una solución de glutamato $2.0 \mathrm{M}$ (en buffer de acople) y $0.024 \mathrm{~g}$ de cianoborohiduro de sodio, dejando la mezcla en agitación toda la noche a temperatura ambiente. Finalmente, el soporte se lavó con agua, solución de $\mathrm{NaCl}$ 1 M y agua de nuevo. La determinación de la cantidad de glutamato acoplado a la columna se realizó mediante una curva de calibración de glutamato con ninhidrina y la determinación de la presencia de glutamato en las fracciones colectadas en los lavados posteriores al acople.

Una vez comprobado el acople, se realizó la cromatografía de afinidad usando la fracción FI concentrada. La columna se equilibró con Tris- $\mathrm{HCl} 50$ mM pH 7.5; Tritón X-100 0.1\% y este mismo buffer fue usado para elución de la fracción no retenida. El volumen de muestra sembrado fue de $5 \mathrm{~mL}(8.8 \mathrm{mg} /$ $\mathrm{mL}$ ) esto se eluyó con el buffer mencionado anteriormente, haciendo un seguimiento de absorbancia a $280 \mathrm{~nm}$ hasta obtener nuevamente la línea base. La fracción retenida se eluyó con Gly-HCl 50 mM, Tritón $\mathrm{X}-1000.1 \% \mathrm{pH} 2.4$, colectándose fracciones de $0.85 \mathrm{~mL}$ a los cuales se les adicionaba previamente $0.15 \mathrm{~mL}$ de buffer Tris-OH $\mathrm{pH}$ 11.4. La presencia de proteína se detectó por seguimiento de absorbancia a $280 \mathrm{~nm}$.

Cuantificación. Para determinar la concentración de proteína presente se utilizó el método del ácido bicinconínico (19) en microplacas, utilizando como patrón albúmina sérica bovina (BSA) de $1.59 \mathrm{mg} /$ $\mathrm{mL}$. Esta determinación se realizó a todos los extractos y fracciones obtenidas en cada uno de los pasos cromatográficos.

Biotinilación de la conantokina G. Se biotinilaron $0.2 \mathrm{mg}$ de Conantokina G (Bachem $\AA$ ) con $0.1 \mathrm{mg}$ de biotina (SulfoNHS-LCBiotina) (20) en $200 \mu \mathrm{L}$ de PBS 150 $\mathrm{mM} \mathrm{pH} \mathrm{7.4.} \mathrm{Se} \mathrm{realizó} \mathrm{el} \mathrm{control} \mathrm{mediante}$ DOT-BLOT (método descrito posteriormente) del péptido biotinilado en diluciones seriadas de $1: 100 ; 1: 500 ; 1: 1000$.

Ensayos de identificación. Para determinar la presencia de la subunidad NR2B se utilizaron las siguientes técnicas:
DOT-BLOT (21). Se tomó una membrana de nitrocelulosa de $6 \mathrm{~cm} \times 3 \mathrm{~cm}$, se sembraron las muestras por duplicado tomando como control $5 \mu \mathrm{L}$ de PBS-BSA $1.3 \%$. Las muestras usadas correspondieron a $5 \mu \mathrm{L}$ de los extractos y fracciones de cromatografías realizadas, los cuales se fijaron a la membrana durante 2 horas a temperatura ambiente. Paso seguido se realizó el bloqueo de la membrana usando PBS-BSA 1.3\% durante 4 horas a temperatura ambiente y toda la noche a $4^{\circ} \mathrm{C}$. Posteriormente se retiró la solución de bloqueo y se lavó la membrana con PBS-Tween 20 0.1\%. Se realizó este lavado tres veces consecutivas.

Seguidamente se adicionó una solución de anticuerpo primario (AntiNR2B (SantaCruz (B) $0.2 \%$ en PBS-BSA $1.3 \%$ ) a la membrana, durante 2 horas a temperatura ambiente. Enseguida se procedió a retirar la solución de anticuerpo primario y se lavó 3 veces la membrana con PBS-Tween 20 0.1\%. Se adicionó solución de anticuerpo secundario (Anti IgG de conejo generado en cabra acoplado a peroxidasa (Sigma $®$ ) $0.2 \%$ en PBS-BSA $1.3 \%$, por 1 hora a temperatura ambiente. Pasado este tiempo se retiró la solución de anticuerpo secundario y se lavó 3 veces la membrana con PBS-Tween $200.1 \%$. Posteriormente se adicionó la solución reveladora $(10 \mathrm{~mL}$ de PBS, $5 \mathrm{mg}$ de diaminobencidina "DAB" y $10 \mu \mathrm{L}$ de peróxido de hidrógeno al $30 \%$ ). Finalmente la membrana se lavó con PBS-Tween 20 $0.1 \%$.

Ensayo de ELISA (17). Para el ensayo de ELISA se sensibilizó una placa de poliestireno NUNC-Maxisorp F-16 con las fracciones recolectadas de las cromatografías de los diferentes estados de purificación, tomando como controles extractos crudos (se utilizaron 3 controles). El ensayo se realizó por duplicado, fijando inicialmente $2,10,20$ y $40 \mu \mathrm{g}$ de proteína en cada pozo y adicionando $150 \mu \mathrm{L}$ de buffer carbonato $50 \mathrm{mM} \mathrm{pH} 9.6$ e incubando a $37^{\circ} \mathrm{C}$ durante 3 horas y a $4^{\circ} \mathrm{C}$ durante 12 horas. Seguidamente se lavó la placa 3 veces con PBS-Tween $200.1 \%$ y se adicionaron 200 $\mu L$ de PBS-BSA $1.3 \%$ llevando a incubación a $37^{\circ} \mathrm{C}$ por 3 horas y luego a $4^{\circ} \mathrm{C}$ durante 12 horas. Se retiró la solución de bloqueo 
y se lavó de nuevo 3 veces con PBS-Tween $200.1 \%$. Seguidamente se adicionaron 200 $\mu \mathrm{L}$ de AntiNR2B $0.2 \%$ en PBS-BSA $1.3 \%$ como anticuerpo primario a las fracciones y al control 2. A los controles 1 y 3 se adicionaron $200 \mu \mathrm{L}$ de PBS-BSA 1.3\%. La placa se llevó a incubación durante 1 hora a $37^{\circ} \mathrm{C}$ y luego a $4^{\circ} \mathrm{C}$ durante 1 hora. Se retiró el anticuerpo primario y se lavó la placa 3 veces con PBS-Tween $200.1 \%$. Se adicionaron $200 \mu \mathrm{L}$ de anti IgG de conejo generado en cabra $0.2 \%$ en PBS-BSA $1.3 \%$ al control 3 y a las fracciones. A los controles 1 y 2 se adicionaron $200 \mu \mathrm{L}$ de PBS-BSA $1.3 \%$. La placa se llevó a incubación durante 1 hora a $37^{\circ} \mathrm{C}$ y luego a $4^{\circ} \mathrm{C}$ durante 1 hora. Posteriormente se retiró el anticuerpo secundario y se lavó la placa 3 veces con PBS-Tween $200.1 \%$. Se adicionaron a todos los pozos $200 \mu \mathrm{L}$ de revelador $(3 \mathrm{mg}$ de ABTS en $10 \mathrm{~mL}$ de buffer citrato-fosfato $\mathrm{pH}$ 5.0 más $15 \mu \mathrm{L}$ de peróxido de hidrógeno al $30 \%$ ), se dejó la placa en la oscuridad y se determinó la absorbancia a $415 \mathrm{~nm}$ en lector de microplacas modelo 550 (BioRad ${ }^{\mathrm{TM}}$ ) a los 15,30 y 45 minutos de reacción.

\section{Imnumotransferencia WESTERN BLOT.} Electroforesis SDS-PAGE. Se realizó de acuerdo con el método de Laemmli (17) usando geles de $8 \mathrm{~cm}$ de longitud, al $12.5 \%$ $\mathrm{T}, 5 \% \mathrm{C}$. Las muestras se mantuvieron en baño de agua en ebullición durante 5 minutos. Se prepararon dos geles idénticos y se corrieron a $120 \mathrm{~V}, 70 \mathrm{~mA}$ hasta final del gel. El gel se tiño con azul de Coomasie R-250.

WESTERN-BLOT (17). Los 2 geles obtenidos de SDS-PAGE $12.5 \%$ se transfirieron a membranas de nitrocelulosa (previamente tratadas con buffer de transferencia), en cámara de transferencia ( $14 \mathrm{~V}, 67 \mathrm{~mA}, 1 \mathrm{~W}$, durante 35 minutos). Luego las membranas se bloquearon con PBS-BSA $1.3 \%$ durante 4 horas a temperatura ambiente y toda la noche a $4^{\circ} \mathrm{C}$. Se retiró la solución de bloqueo y se lavó la membrana con PBS-Tween 20 $0.1 \%$. A una de las membranas se adicionó solución de anticuerpo primario (AntiNR2B $0.2 \%$ en PBS-BSA $1.3 \%$ ) durante 2 horas a temperatura ambiente. Enseguida se procedió a retirar la solución de anticuerpo primario y se lavó la membrana con PBS-
Tween 20 0.1\%. Posteriormente se adicionó solución de anticuerpo secundario (Anti IgG de conejo generado en cabra $0.2 \%$ en PBS-BSA $1.3 \%$ ), por 1 hora a temperatura ambiente. Pasado este tiempo se retiró la solución de anticuerpo secundario y se lavó la membrana con PBS-Tween 20 0.1\%. Finalmente se adicionó la solución reveladora (10 $\mathrm{mL}$ de PBS, $5 \mathrm{mg}$ de diaminobencidina "DAB", y $10 \mu \mathrm{L}$ de peróxido de hidrógeno al $30 \%$ ) hasta coloración esperada. Se lavó con PBS-Tween 20 0.1\%.

A la otra membrana de nitrocelulosa se adicionó solución de conantokina Gbiotinilada al $0.2 \%$ en PBS durante 2 horas a temperatura ambiente. Enseguida se procedió a retirar la solución y se lavó la membrana con PBS-Tween 20 0.1\%. Se adicionó solución de Estreptavidina peroxidasa $0.2 \%$ en PBS por 1 hora a temperatura ambiente. Pasado este tiempo se retiró esta solución y se lavó la membrana con PBS-Tween 20 0.1\%. Finalmente se adicionó la solución reveladora $(10 \mathrm{~mL}$ de PBS, $5 \mathrm{mg}$ de Diaminobencidina "DAB", y $10 \mu \mathrm{L}$ de peróxido de hidrógeno al $30 \%$ ). Posteriormente la membrana se lavó con PBS-Tween $200.1 \%$.

Histoquímica. Para determinar la presencia de la subunidad, se realizaron ensayos de histoquímica sobre cortes de hipocampo de cerebro de rata a los cuales se les hizo interactuar con conantokina biotinilada o antiNR2B y la detección se realizó por el sistema estreptavidina peroxidasa (el protocolo fue realizado con Vecstain $A B C$ (Avidin-Biotin complex)) y DBA como sustrato. Se lavaron los tejidos tres veces con PBS-Tritón X-100 0.3\% en intervalos de 4 minutos y posteriormente con PBS. Se adicionó PBS- $\mathrm{H}_{2} \mathrm{O}_{2} 3 \%$ por una hora a temperatura ambiente y se lavaron lo tejidos con PBS-Tritón X-100 $0.3 \%$ en los mismos intervalos de tiempo. Los cortes de cerebro se dividieron en dos grupos para los ensayos con anticuerpos y los ensayos con Conantokina-G biotinilada.

Inmunohistoquímica (17). Después del lavado con PBS-Tritón X-100 0.3\% se adicionaron $2 \mathrm{~mL}$ de anticuerpo primario (AntiNR2B $0.2 \%$ en PBS-BSA $1.3 \%$ ), 
durante 2 horas a temperatura ambiente. Enseguida se procedió a retirar la solución de anticuerpo primario y se lavó el tejido con PBS-Tritón X-100 $0.3 \%$ tres veces en intervalos de tiempo de 4 minutos en cada lavado. Se adicionaron $2 \mathrm{~mL}$ de anticuerpo secundario (Anti IgG de conejo generado en cabra, $0.2 \%$ en PBS-BSA $1.3 \%$ ), por 1 hora a temperatura ambiente. Pasado este tiempo se retiró la solución de anticuerpo secundario y se lavó el tejido con PBSTritón $\mathrm{X}-100 \quad 0.3 \%$ dos veces y un tercer lavado con PBS en intervalos de tiempo de 4 minutos en cada lavado. Finalmente se adicionó la solución reveladora $(10 \mathrm{~mL}$ de PBS, $5 \mathrm{mg}$ de Diaminobencidina "DAB", y $10 \mu \mathrm{L}$ de peróxido de hidrógeno al 30\%).

Ensayo con péptido (Conantokina GBotinilada). Después del lavado con PBSTritón X-100 0.3\% se adicionaron $2 \mathrm{~mL}$ de Conantokina G-biotinilada $0.2 \%$ en PBS durante 2 horas a temperatura ambiente. Enseguida se procedió a retirar la solución de péptido y se lavó el tejido con PBSTritón X-100 0.3\% tres veces en intervalos de tiempo de 4 minutos en cada lavado. Se adicionaron $2 \mathrm{~mL}$ de estreptavidina peroxidasa $0.2 \%$ en PBS por 1 hora a temperatura ambiente. Pasado este tiempo se retiró la solución y se lavó el tejido con PBS-Tritón X-100 0.3\% dos veces y un tercer lavado con PBS en intervalos de tiempo de 4 minutos en cada lavado. Finalmente se adicionó la solución reveladora $(10 \mathrm{~mL}$ de PBS, $5 \mathrm{mg}$ de Diaminobencidina "DAB", y $10 \mu \mathrm{L}$ de peróxido de hidrógeno al 30\%).

Los cortes de tejido fueron observados en microscopio óptico a una amplificación total de $100 x$.

\section{RESULTADOS}

Los datos iniciales de concentración de proteína varían entre $4.2 \mathrm{mg} / \mathrm{mL}$ y 4.8 $\mathrm{mg} / \mathrm{mL}$ para los 5 extractos obtenidos mediante la metodología 1 y entre 4.5 $\mathrm{mg} / \mathrm{mL}$ y $5.0 \mathrm{mg} / \mathrm{mL}$ para los obtenidos mediante la metodología 2. Ante estos valores, se evidenció que la concentración de proteína obtenida es muy similar y que no hay diferencias marcadas entre estos dos métodos de extracción.
Al realizar la cromatografía de exclusión molecular con cada uno de los extractos obtenidos, se observa que el perfil obtenido es similar en todos los casos, y se muestra la presencia de dos picos de absorbancia, los cuales se nombran como FI y FII (Figura 1).

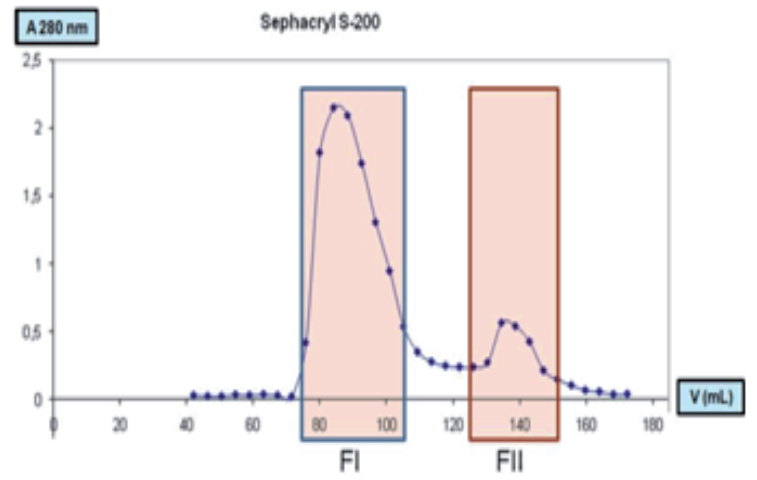

Figura 1. Cromatografía de exclusión molecular (Perfil cromatográfico). Obtención de fracciones I y II por cromatografía sobre Sephacryl S-200 realizada a extractos obtenidos por los métodos de extracción 1 y 2 .

Comparando los dos métodos de extracción del receptor NMDA como complejo, el que presentó mayor efectividad de acuerdo con la cantidad de proteína extraída en la fracciones FI o de alto peso molecular de cromatografía de exclusión molecular S-200, fue el descrito como método 2 (Figura 2).Los datos encontrados para las proteínas de bajo peso molecular (Fracción II), muestran que el método 1 permite obtener una mayor cantidad de proteínas con esta característica (Figura 2).

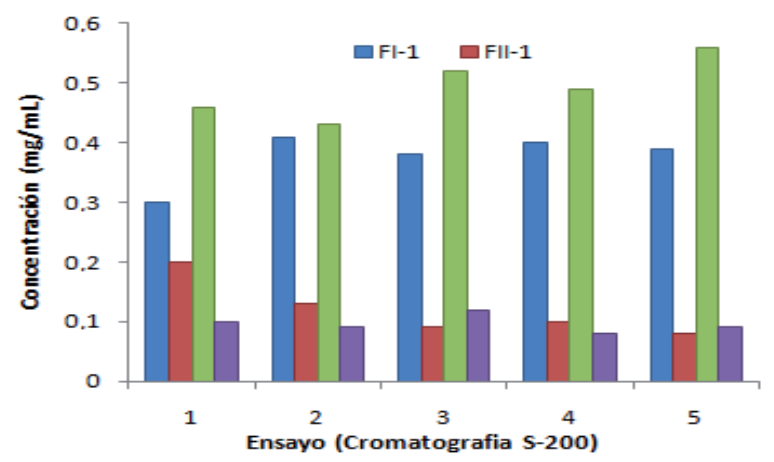

Figura 2. Cuantificación de proteína de S-200. Concentración $(\mathrm{mg} / \mathrm{mL})$ de proteína en fracciones I y II de Cromatografía sobre Sephacryl S-200 realizadas a extractos obtenidos por método 1 y 2 . 
De igual manera los ensayos realizados mediante la prueba de ELISA permitieron observar que el método 2 para la extracción de la subunidad NR2B es más efectivo frente al método 1 de extracción. (Figura 3).

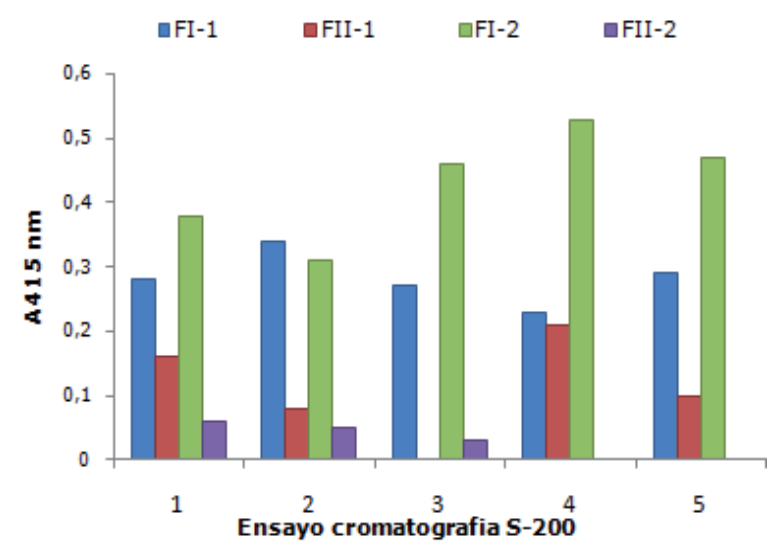

Figura 3. Presencia de la subunidad NR2B. Determinación de la presencia de la subunidad NR2B en las fracciones obtenidas a partir de los extractos de cerebro de rata, por medio de la prueba de ELISA a fracciones I y II.

La extracción de la subunidad se realizó mediante la metodología 2 , seguida de la realización de la cromatografía de exclusión molecular usando Sephacryl S-200. Las fracciones I (FI) de las diferentes cromatografías realizadas fueron reunidas y concentradas mediante ultrafiltración. Éstas se utilizaron para la realización de la cromatografía de afinidad de acuerdo con las especificaciones mostradas en la metodología.

El perfil cromatográfico obtenido al realizar la cromatografía de afinidad presenta dos picos característicos, uno de los cuales corresponde a la fracción no retenida y el otro, a la fracción retenida. (Figura 4). El pico número 1 presenta una alta concentración de proteína, la cual es eluída uniformemente del soporte activado. El pico número 2 requiere del uso de un $\mathrm{pH}$ ácido para su liberación del soporte y representa una porción muy pequeña de la cantidad de proteína presente en el extracto utilizado para esta cromatografía. Se reunieron varias fracciones retenidas y se concentraron hasta reducir su volumen cerca de diez veces (ultrafiltración).

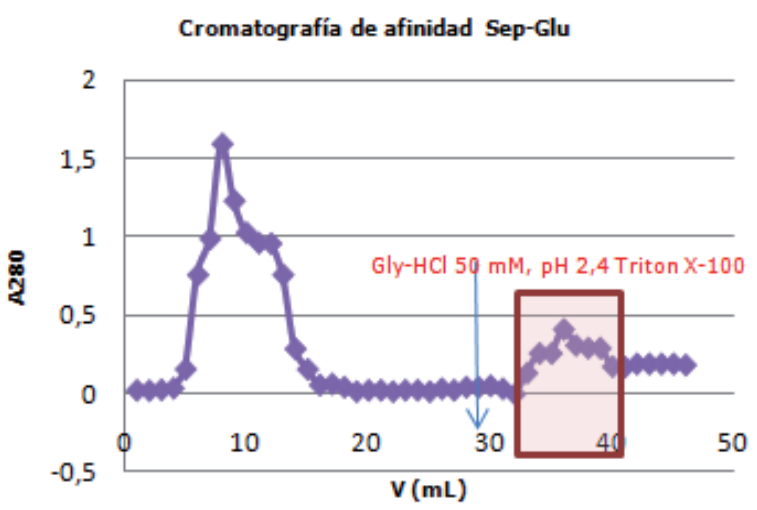

Figura 4. Cromatografía de afinidad. Perfil de Cromatografía de afinidad sobre Sepharosa 4B-NHS-Glu realizada a fracciones I obtenidas por cromatografía S-200.

Los extractos crudos y las diferentes fracciones de las cromatografías realizadas fueron cuantificadas por ácido bicinconínico (BCA). Los valores oscilan entre $12 \mathrm{mg} /$ $\mathrm{mL}$, correspondiente a extracto crudo concentrado por ultrafiltración, hasta 0.1 $\mathrm{mg} / \mathrm{mL}$ de una fracción II de exclusión molecular (Figura 5).

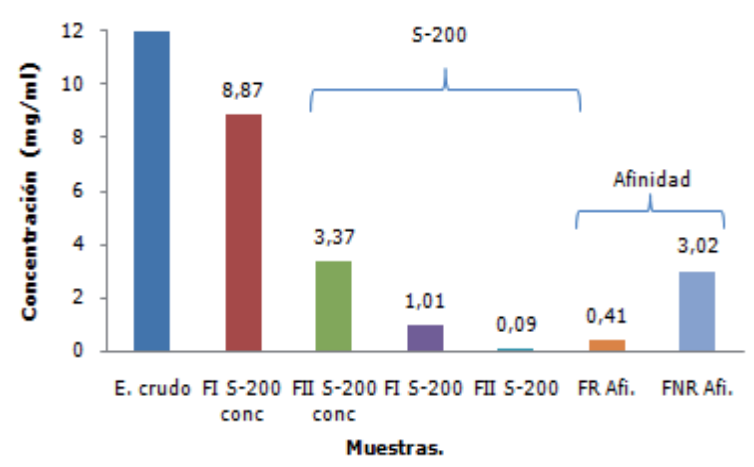

Figura 5. Cuantificación de proteína por BCA. Concentración de proteína cuantificada por BCA de Extracto crudo, Fracciones I y II de cromatografía sobre sephacryl S-200 y concentrados de estas fracciones. Así como fracciones retenidas y no retenidas de cromatografía de afinidad.

Los ensayos de ELISA (Figura 6) y DOTBLOT permitieron detectar la presencia de la subunidad NR2B, presentando un reconocimiento del anticuerpo primario (AntiNR2B) hacia la subunidad de acuerdo con el patrón de marcación exhibido (Figura 7A1). Por esta técnica igualmente se evidenció la biotinilación de la conantokina 
G, lo cual se observó por el reconocimiento generado por la estreptavidina peroxidasa y su posterior revelado con DAB (Figura 7A2).

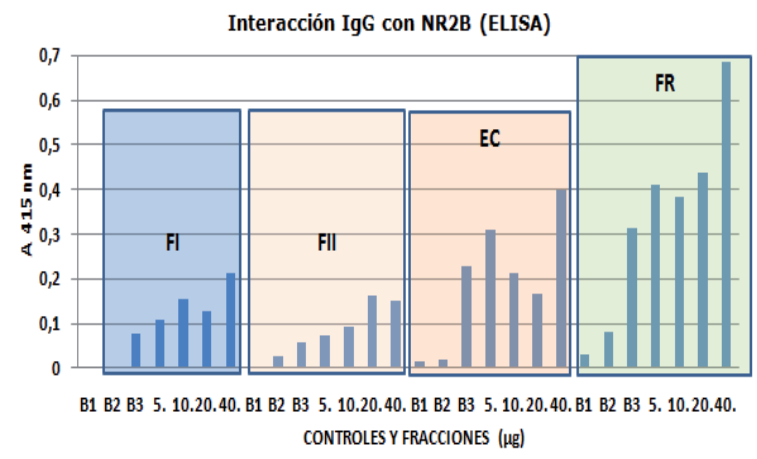

Figura 6. Ensayo de ELISA. Resultados de ELISA realizado a diferentes extractos (EC, Extracto crudo, FI y FII de cromatografía de exclusión molecular y FR, fracción retenida de cromatografía de afinidad y $B$, control), utilizando ANTI-NR2B para reconocer la subunidad.

Con el péptido biotinilado se realizaron ensayos de ELISA comparando la interacción de este péptido marcado y la obtenida por el anticuerpo AntiNR2B con la subunidad. Los resultados obtenidos cuando se utilizó el péptido biotinilado, mostraron que no se había generado interacción con la subunidad que se encontraba en cada una de las fracciones utilizadas para este ensayo (extracto crudo, FI y FII de cromatografía de exclusión molecular y Fracción retenida de cromatografía de afinidad), independientemente de la cantidad de proteína presente en cada uno de los pozos del ensayo. Los valores obtenidos a diferentes tiempos de revelado, se encontraban similares a los generados por los controles utilizados (datos no mostrados). De manera contraria a los resultados anteriores, la utilización del anticuerpo comercial mostró una buena interacción con cada una de las fracciones utilizadas y una tendencia a aumentar el valor de absorbancia obtenido después del revelado, de acuerdo con el aumento de la cantidad de proteína utilizada $(5,10,20$ y $40 \mu \mathrm{g}$ ) en cada pozo del ensayo (Figura 6).

Adicionalmente se muestra que el reconocimiento se hace más evidente al interactuar con las fracciones retenidas obtenidas por la cromatografía de afinidad, seguida por las fracciones de extracto crudo FI y FII de cromatografía de exclusión

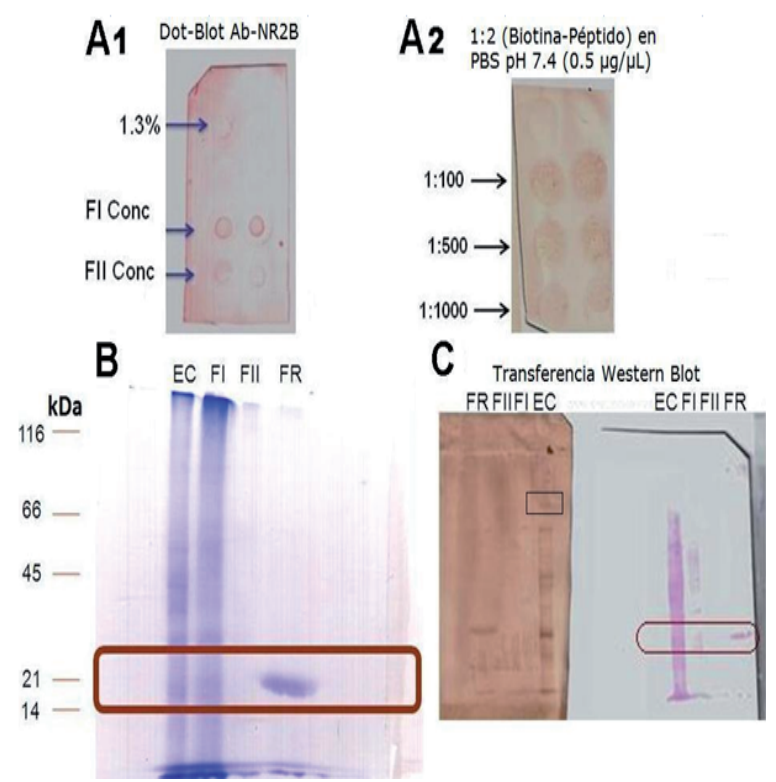

Figura 7. DOT BLOT. Se identifica en (A1) la presencia de la subunidad NR2B en diferentes fracciones obtenidas por cromatografía de exclusión molecular, y en (A2) la marcación generada en la conantokina $\mathrm{G}$ biotinilada a diferentes diluciones. Electroforesis SDS-PAGE. Extracto crudo y fracciones en (B) $(12,5 \% \mathrm{~T}, 5 \% \mathrm{C})$ y transferencia (C) a membrana de nitrocelulosa de extracto crudo (EC), fracción I y II (FI y FII) de cromatografía de exclusión molecular y fracción retenida (FR) de cromatografía de afinidad. La transferencia se verificó por tinción con Rojo Pounceau (C, derecha) y el WESTERN-BLOT se realizó con Anti-NR2B.

molecular. Estos datos corroboran los obtenidos por DOT-BLOT ya que allí también se evidenció la interacción con la subunidad NR2B presente en la fracción I y en menor proporción, en la FII de la cromatografía de exclusión molecular.

La electroforesis SDS-PAGE mostró una banda de alto peso molecular que podría corresponder a la subunidad NR2B (mayor a $100 \mathrm{kDa}$ en Extracto crudo y FI) y una banda de bajo peso molecular, cercano a $21 \mathrm{kDa}$ presente en la fracción retenida de afinidad. (Figura 7B). Al realizar la transferencia a membrana de nitrocelulosa e identificar la subunidad NR2B por el anticuerpo 0 , separadamente, por el péptido biotinilado, nuevamente se encontró un buen reconocimiento por parte del anticuerpo, el cual marcó una banda de alto 
peso molecular en el extracto crudo y la FI, pero, contrario a lo esperado, reconoció también la banda de bajo peso molecular en la fracción retenida de la cromatografía de afinidad (Figura 7C). Los resultados obtenidos al usar el péptido biotinilado para identificar interacción en las mismas fracciones mostraron que no se generaba la interacción ni con la banda de alto peso molecular del extracto crudo y FI ni con la banda de bajo peso molecular presente en la fracción retenida de la cromatografía de afinidad (datos no mostrados).

Los resultados obtenidos en la histoquímica (Figura 8) muestran que la interacción generada con la conantokina biotinilada no fue efectiva ya que la coloración y el marcaje obtenido fueron similares a los resultados obtenidos con el control negativo.

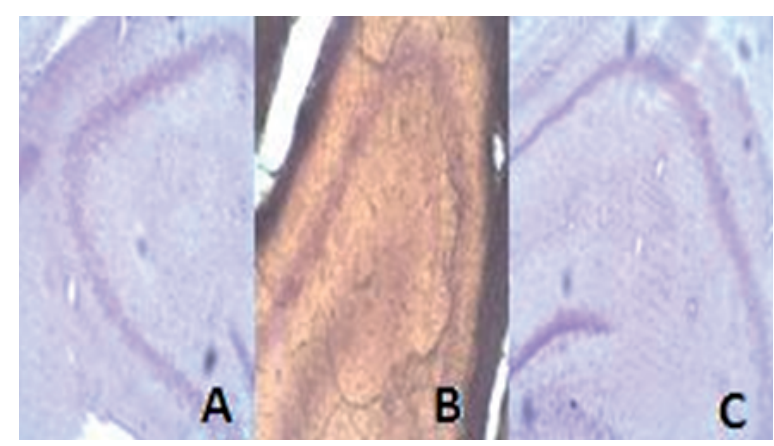

Figura 8. Histoquímica de cortes de hipocampo de cerebro de rata. A. Control negativo. La tinción mostrada es hematoxilina-Eosina. B. Control positivo. Corte tratado con anti-NR2B y revelado con $D A B$. Contracoloración de hematoxilina-Eosina. C. Corte tratado con Conantokina biotinilada y revelado con DAB. Contracoloración de hematoxilina-Eosina. Amplificación total: 100X.

El control positivo utilizado (tratado con anti-NR2B) si mostró un reconocimiento marcado en las zonas que se han descrito previamente como las que presentan una mayor cantidad de este receptor (Hipocampo).

\section{DISCUSIÓN}

El receptor de glutamato tipo NMDA es un blanco farmacológico de gran importancia debido a su incidencia en desórdenes neurológicos como epilepsia, Alzheimer,
Parkinson, Huntington, entre otros. En todos estos casos, una de las subunidades que parece tener un mayor grado de importancia es la subunidad NR2B ubicada en membrana de regiones postsinápticas de células nerviosas (22). Por tanto es necesario establecer una metodología que permita la purificación y análisis de dicha subunidad. En este caso particular se ensayaron dos metodologías de extracción, la primera (metodología 1) (17) la cual presenta ciertas modificaciones respecto a lo reportado en la segunda (metodología 2) se pretendió hacer una purificación previa mediante la utilización de un buffer de extracción que no posee detergentes y solubiliza proteínas no hidrofóbicas, dejando en el pellet de la primera centrifugación las proteínas que sean componentes de membranas ya que éstas requieren el uso de detergentes para su solubilización.

De acuerdo con el comportamiento e interacción del glutamato como agonista de la subunidad NR2B, se realizó el acople del glutamato al soporte de Sepharosa-4B previamente activado (18). El éxito del acople del glutamato al soporte se evidenció nuevamente por la obtención de una fracción retenida a partir de los extractos que fueron sembrados sobre esta columna. De acuerdo con los perfiles obtenidos (Figura 4), se evidenció que existe esta fracción retenida, la cual se eluye al modificar las condiciones de $\mathrm{pH}$ en el buffer de elución. El peso molecular de la proteína obtenida por esta cromatografía, se encuentra cercano a los $21 \mathrm{kDa}$ que es un peso molecular muy bajo para cualquiera de las subunidades del receptor NMDA. Sin embargo, se puede ver cómo el anticuerpo utilizado reconoce esta banda con la misma intensidad que lo hace con una banda de peso molecular alto (160 kDa), que corresponde a la subunidad NR2B (Figura 7). Hasta el momento, no se ha descrito en la literatura un fragmento tan pequeño ( $21 \mathrm{kDa}$ ) que corresponda a una sección de la subunidad NR2B. Sin embargo, nuestros resultados sugieren que dicho fragmento se puede encontrar y que podría corresponder a una sección del dominio extracelular que está comprometido con el reconocimiento al glutamato. Esta afirmación se sustenta con los resultados de afinidad, ELISA y WESTERN-BLOT (Figuras 4,6 y 7 ). 
Teniendo en cuenta la alta afinidad de la conantokina $\mathrm{G}$ por la subunidad NR2B y la poca reacción cruzada con otros receptores presentes en tejido cerebral, se utilizó este péptido para determinar la presencia de la subunidad mediante ensayos de WESTERN y DOT-BLOT. En estos ensayos se observó la interacción que tienen los anticuerpos en el reconocimiento de la subunidad, resultados que se comprueban con el ensayo de histoquímica, donde se presentan características propias a la detección por DAB y hematoxilina (reacciones coloreadas). Pero en el caso del péptido biotinilado no se presentan los resultados característicos a un marcaje de la conantokina $G$ por la biotina como método directo de interacción.

Puesto que la biotina se une de forma covalente a cadenas laterales amino o extremos amino terminales de aminoácidos, la unión de la conantokina en la biotinilación se haría en el residuo de lisina 15 y en la glicina 1 del péptido, residuos que pueden participar fuertemente en la interacción entre estas dos moléculas (13). Análisis computacionales (datos no mostrados), muestran que la incorporación de la biotina en la estructura de un péptido tan pequeño como la conantokina, modifica grandemente su campo energético y por tanto, su superficie molecular, lo que inevitablemente resulta en pérdida de los sitios de unión entre el péptido y la subunidad. Esto significaría que se genera un impedimento de tipo estérico que impediría el reconocimiento de los aminoácidos glutamato $2, \gamma$-carboxiglutamato 4 e isoleucina 12 del péptido.
En conclusión, si se da el acople de dos moléculas de biotina hacia la conantokina $\mathrm{G}$, esas biotinas se presentarían como grupos voluminosos capaces de interferir en la afinidad del péptido marino hacia la subunidad NR2B, hecho que resulta ser valedero al momento de explicar la no interacción de la subunidad con el péptido biotinilado para su posterior reconocimiento por la estreptavidina peroxidasa.

Ahora bien, debido a la importancia del receptor NMDA en los procesos de aprendizaje, memoria y plasticidad neuronal, mediados por el transporte de calcio a través del canal asociado a dicho receptor, es preciso continuar en la comprensión del funcionamiento de este tipo de receptores ionotrópicos. Por tanto se hace necesario buscar una forma de marcaje de la conantokina $\mathrm{G}$ que no afecte la interacción y reconocimiento de este tipo de péptidos por la subunidad NR2B, además de identificar la banda de peso molecular bajo que se obtuvo en la purificación por cromatografía de afinidad y que es reconocida por el anticuerpo primario AntiNR2B.

\section{Agradecimientos}

Al Dr. Leonardo Lareo y a los Doctores Gerardo Pérez y Nohora Vega del Grupo de Investigación en Proteínas. A la Vicerrectoría de Investigación de la Universidad Nacional de Colombia (División de Investigación-Sede Bogotá).

\section{REFERENCIAS}

1. Furukawa $H$, Singh $S K$, Mancusso $R$, Gouaux E. Subunit arragement and function in NMDA receptors. Nature 2005; 438: 185-192.

2. Loftis J, Janowsky A. The N Metyl D Aspartate Receptor Subunit NR2B: Localization, Funcional Properties, Regulation, and Clinical Implications. Pharmacol Ther 2003; 97: 55-85.

3. Ali DW, Alter MW. NMDA receptor regulation by Src kinase signaling in excitatory synaptic transamission and plasticity. Curr Opin Neurobiol 2001; 11: 336-342.

4. Clarke RJ, Johnson JW. Voltajedependent gating of NR1/2B NMDA receptors. J Physiol 2008; 586: 5727-5741.

5. Ishii T, Moriyoshi K. Molecular characterization of the family of the N-Methyl-D- Asparatate receptor subunits. J Biol Chem 1993; 268: 2836-2843. 
6. Matsuda K, Fletcher M, Kamiya Y, Yusaki $M$. Specific assembly with the NMDA receptor $3 B$ subunit controls surface expression and calcium permeability of NMDA receptors. J Neurosci 2003; 23:10064-10073.

7. Eriksson M, Nilsson A, Froeich-fabre $S$, Akesson E, Dunker J, Seiger A, et al. Cloning and expression of the human N-methyl-D-Aspartate receptor subunit NR3A. J Neurosci 2002; 321:177-181.

8. Nishi $M$, Hinds $H$, LU HP, Kawata $M$, Hayashi Y. Motor neuronspecificexpression of NR3B, a novel NMDA-type glutamate receptor subunit that works in a dominant-negative manner. J Neurosci 2001; 21:RC185.

9. Donevan SD, McCabe RT. Conantokin $G$ Is an NR2B-Selective Competitive Antagonist of $\mathrm{N}$-Methyl-d-aspartate Receptors. Mol Pharmacol 2000; 58:614-623.

10. Kew JN, Kemp JA. Ionotropic and metabotropic glutamate receptor structure and pharmacology. Psychopharmacology (Berl) 2005; 179:4-29.

11. Wenthold RJ, Prybylowski K, Standley S, Sans N, Petralia RS. Trafficking of NMDA receptors. Annu Rev Pharmacol Toxicol 2003; 43:335-58.

12. Khann A, Stanley $M$, Bozzetti $L$, Chin C, Stivers C, Curras-collazo MC. N-Methyl-D-Aspartate receptor subunit NR2B is widely expressed throughout the rat diencephalon: an inmunohistochemical study. J Comp Neurol 2000; 428:428-449.

13. Tamas Blandl, Jaroslav Zajicek, Mary Prorok, Castellino J. Sequence Requirements for the N-Methyl-Daspartate Receptor Antagonist Activity of Conantokin-RJ. Biol Chem 2001; 276:7391-7396.

14. Williams AJ, Dave JR, Phillips JB, Lin Y, McCabe RT, Tortella FC. Neuroprotective efficacy and therapeutic window of the high-affinity $\mathrm{N}$ - methyl - D - Aspartate antagonist Conantokin-G: In vitro (primary cerebellar neurons) and In vivo (Rat model of transient focal brain ischemia) studies. J Pharmacol Exp Ther 2000; 294(1):378-386.

15. Adams AC, Layer RT, McCabe RT, Keefe $K A$. Effects of conantokins on $L-3$, 4-dihydroxyphenylalanine - induced behavior and immediately early gene expression. Eur J Pharmacol 2000; 404(3):303-313.

16. Mortari MR, Siqueira AO, Brandao L, Ferreira dos Santos W. Neurotoxins from invertebrades: From basic research to therapeutic application. Pharmacol Ther 2007; 114(2):171-183.

17. Reyes E, Lareo L, Chow DC, Pérez G. Immunolocalization and Biochemical Characterization of $\mathrm{N}$-methyl-Daspartate Receptor Subunit NR1 from Rat Brain. Protein J 2006; 25(2): 95-108.

18. Méndez G, Reyes EA, Poutou R, Quevedo B, Lareo Leornardo. Purificación de IgY contra la subunidad NR3 del receptor NMDA de cerebro de rata. Rev MVZ Córdoba 2008; 13(1):1146-1156.

19. Smith P, Rohn R, Hermanson G, Mallia A, Gartner F, Provenzano M. Measurement of protein using Bicinchoninic Acid. Anal Biochem 1985; 150:76-85.

20. Marsden KC, Beattie J, Friedenthal J, Carroll RC. NMDA Receptor Activation Potentiates Inhibitory Transmission through GABA Receptor-Associated Protein-Dependent Exocytosis of GABAA Receptors. J Neurosci 2007; 27(52):14326-14337.

21. Woof J, Burton D. Human antibody Fc receptor interactions iluminated by cristal structures. Nat Rev Inmunol 2004; 4:1-11.

22. Paoletti $P$, Neyton J. NMDA receptor subunits: function and pharmacology. Curr Opin Pharmacol 2007; 7(1):39-47. 